\title{
ESPECTROSCOPIA RAMAN DE COSTO REDUCIDO PARA LA IDENTIFICACIÓN DE LÍQUIDOS TRANSPARENTES
}

\section{Oscar Urquidi}

\section{RESUMEN}

El trabajo presenta el desarrollo de un sistema de espectroscopia Raman de costo reducido (menor a 1000 USD), destinando a la detección de líquidos transparentes no identificables por métodos colorimétricos. Dadas las necesidades (en Bolivia) de control y fiscalización de compuestos químicos en productos locales e importados, el desarrollo de sistemas espectroscópicos moleculares se perfila como una solución accesible. El sistema desarrollado se basó en un espectrómetro clásico modificado, con una resolución de $2 \mathrm{~nm}$ y un ancho espectral de $200 \mathrm{~nm}$. Para la generación de la dispersión Raman se usó un diodo láser de $405 \mathrm{~nm}$ y $5 \mathrm{~mW}$ acoplado a un recipiente transparente y una lente auxiliar para la proyección de la luz sobre el plano de entrada. Como detector se usó una cámara CCD con refrigeración termoeléctrica, cuyas imágenes se integraron verticalmente para la obtención de los espectros. Como parte de las pruebas de validación, se obtuvieron espectros Raman de agua, etanol y acetato de etilo. Así mismo, se obtuvo el espectro de una mezcla de etanol y agua. En todos los casos se observó coincidencia entre los espectros obtenidos y los de referencia, validando su correcta detección. Como punto de mejora, se identificó la adición de filtros de corte específicos para mejorar el contraste y la resolución del sistema. Dados estos resultados, el sistema mostró un gran potencial como una herramienta analítica de bajo costo para compuestos moleculares.

Palabras Clave: Espectroscopia, Espectroscopia Raman, Espectroscopia Molecular, Espectroscopia Láser.

DOI: 10.23881/idupbo.019.1-6i 